\title{
MENYAMBUT PISA 2018: PENGEMBANGAN LITERASI MATEMATIKA UNTUK MENDUKUNG KECAKAPAN ABAD 21
}

\author{
Enika Wulandari' ${ }^{1}$, Raekha Azka ${ }^{2}$ \\ IAIN Salatiga ${ }^{1}$, UIN Sunan Kalijaga Yogyakarta ${ }^{2}$ \\ pos-el : enika.wulandari@gmail.com¹, raekha.azka@gmail.com²
}

\begin{abstract}
ABSTRAK
Era global menuntut kecakapan tertentu dari sumber daya manusia. Salah satu kecakapan yang diperlukan di era global adalah literasi matematika. Literasi matematika merujuk pada kemampuan individu untuk memformulasikan, menggunakan, dan menginterpretasikan matematika dalam berbagai konteks. Penilaian literasi matematika siswa usia 15 tahun secara internasional diukur melalui PISA (Programme for International Student Assessment) yang diselenggarakan oleh OECD (Organization for Economic Cooperation and Development). Indonesia menunjukkan kecenderungan peningkatan literasi matematis mulai tahun 2015. Hal ini ditunjukkan dari ratarata skor literasi matematika yang meningkat dari 375 pada tahun 2012 menjadi 386 pada tahun 2015. Indonesia perlu mempertahankan kecenderungan tersebut pada penilaian PISA tahun 2018. Penelitian ini bertujuan untuk mendeskripsikan karakteristik PISA 2018, faktor-faktor yang mempengaruhi literasi maematika dan pengembangan literasi matematika sebagai kecakapan abad 21. Penelitian ini menggunakan pendekatan kajian teori dengan menelaah dan menganalisis referensi serta hasil penelitian yang relevan. Hasil kajian dapat ditindaklanjuti dengan penelitian selanjutnya untuk mengembangkan literasi matematika siswa.
\end{abstract}

Kata kunci : literasi matematika, PISA, kecakapan abad 21

\section{ABSTRACT}

Global era demanding skill certain of human resources. One skill that is required in the era of global is mathematics literacy. Mathematics literacy refer to the ability of an individual to formulate, use, and the interpretate the mathematics in a range of contexts. Assessment of mathematics literacy students age of 15 in international is measured by PISA (Programme for International Student Assessment) held by OECD (Organization for Economic Cooperation and Development). Indonesia shows the trend of increased mathematics literacy starting in 2015. This is shown by average score of mathematics literacy which jumped from 375 in 2012 be 386 in 2015. Indonesia needs to maintain this tendency on PISA 2018. This study attempts to 2018 describe characteristics of PISA 2018, factors influencing mathematics literacy and development mathematics literacy as $21^{\text {st }}$ century's skill. This study used the study theory with exploring and analyze relevant reference and the results of research. The results of the study will be followed up with further research to develop student's mathematics literacy.

Keywords : mathematics literacy, PISA, $21^{\text {st }}$ century's skill

\section{PENDAHULUAN}

Saat ini dunia memasuki abad 21. Abad 21 yang juga disebut dengan era global mensyaratkan penguasaan terhadap kecakapan tertentu. Dalam tataran internasional, National
Education Association (2011: 5) menyatakan bahwa untuk berkompetisi di era global, siswa harus menjadi proficient communicators, creators, critical thinkers, dan collaborators melebihi sekadar kecakapan membaca, 
menulis, dan aritmatika sebagaimana pada era ekonomi manufaktur dan agraria di Amerika pada kurun waktu 50 tahun sebelumnya. Kecakapan lain yang diperlukan oleh generasi muda di era global adalah karakter. Kementerian Pendidikan dan Kebudayaan (2017: 2) menyatakan bahwa kecakapan yang diperlukan pada abad 21 yaitu literasi dasar, kompetensi, dan karakter. Salah satu literasi dasar yang diperlukan adalah literasi matematika.

Literasi matematika merujuk pada kemampuan individu untuk memformulasikan, menggunakan, dan menginterpretasikan matematika dalam berbagai konteks. Hal ini mengisyaratkan bahwa makna literasi matematika adalah tidak sekadar mampu melaksanakan prosedur dalam penyelesaian masalah matematis tetapi juga mendayagunakan matematika dalam kehidupan sehari-hari. Literasi matematika menuntut dimensi yang lebih luas dari pemahaman dan penerapan yaitu ranah interpretasi. Orang yang menguasai literasi matematika disebut dengan literate (melek) terhadap matematika.

Penilaian terhadap literasi matematika dilaksanakan melalui PISA (Programme for International Student Assessment) yang diselenggarakan oleh OECD (Organization for Economic Cooperation and Development). Penilaian menggunakan metode survey di sejumlah negara. Survey telah dilaksanakan sebanyak enam kali yaitu pada tahun 2000, 2003, 2006, 2009, 2012, dan 2015. Setiap pelaksanaan memiliki fokus penilaian masingmasing yang disebut dengan major. Sebagai contoh, penilaian PISA pada tahun 2012 menempatkan matematika sebagai major sedangkan pada tahun 2015 yang ditempatkan sebagai major adalah sains.

Hasil survey PISA pada kurun waktu tahun 2000 hingga 2015 menunjukkan bahwa skor rata-rata literasi matematika masih di bawah skor rata-rata negara-negara yang mengikuti survey. Hal ini menunjukkan bahwa posisi literasi matematika siswa Indonesia masih di bawah literasi matematika negara-negara di dunia pada umumnya.

Akan tetapi, pada tahun 2015, skor rata-rata literasi matematika mengalami peningkatan. Pada tahun 2012 skor rata-rata literasi matematika adalah 375 sedangkan pada tahun 2015 menjadi 386. Peningkatan terjadi sebesar 11 poin.

Peningkatan tersebut tentunya merupakan hasil dari upaya para guru, wali murid, Kementerian Pendidikan dan Kebudayaan dan seluruh pihak yang terlibat dalam upaya meningkatkan literasi matematika. Apresiasi tersebut terutama diberikan kepada siswa-siswi di Indonesia yang telah bersedia belajar dan berupaya meningkatkan literasi matematisnya.

Saat ini negara-negara di seluruh dunia sedang mempersiapkan diri untuk menghadapi survey PISA pada tahun 2018. Survey direncanakan dilaksanakan pada bulan Agustus 2018. Survey pada tahun 2018 tersebut menjadi tantangan bagi Indonesia untuk mempertahankan kecenderungan (trend) peningkatan skor rata-rata literasi matematika yang mengindikasikan kondisi literasi matematika yang sesungguhnya.

Untuk dapat meningkatkan literasi matematika yang akan diukur melalui 
survey PISA, siswa, guru, dan stakeholder terkait harus mengetahui aspek-aspek apa saja yang dinilai dan strategi untuk mengembangkan literasi matematika.

\section{METODE PENELITIAN}

Metode yang digunakan dalam penelitian ini adalah kajian teori terhadap referensi dan hasil penelitian yang berkaitan dengan literasi matematis. Peneliti menelaah, menganalisis, dan menyusun kesimpulan berkaitan dengan literasi matematis.

\section{HASIL DAN PEMBAHASAN}

Literasi matematis merupakan kemampuan seseorang untuk mengidentifikasi dan memahami peranan matematika dalam kehidupan, membuat keputusan yang dibangun dengan baik dan menggunakan serta terlibat dalam matematika dengan kepentingan kehidupan individu sebagai penduduk yang konstruktif, peduli dan reflektif (OECD, 2006: 12). Dalam definisi tersebut dikemukakan aspek identifikasi, pemahaman, pengambilan keputusan, dan pendayagunaan matematika dalam kehidupan. Dalam definisi tersebut juga diungkap keberadaan individu sebagai bagian dari masyarakat dunia yang disebut dengan penduduk.

Literate terhadap matematika bermakna melek terhadap matematika. Tinjauan lain dalam literate adalah melek sains (science literacy), melek membaca (reading literacy), dan melek finansial (financial literacy).

Ojose (2011: 89) menyatakan bahwa literasi matematis tidak mengindikasikan pengetahuan mendetail mengenai kalkulus, persamaan diferensial, analisis, topologi, aljabar linear, aljabar abstrak, dan rumus matematika yang kompleks dan canggih tetapi lebih kepada sebuah pemahaman yang luas dan penghargaan atas apa yang mampu dicapai dengan matematika. Pernyataan tersebut menunjukkan bahwa literasi matematika tidak diartikan sebagai penguasaan terhadap struktur ilmu matematika saja namun pada aspek yang lebih luas.

Konsep literasi matematis berkaitan dengan konsep lain meliputi pemodelan matematika dan komponen proses yang oleh de Lange disebut dengan matematisasi (Stacey, 2010: 8). Secara lebih lanjut Stacey (2010: 8) menjelaskan bahwa proses matematisasi berkaitan dengan menyusun (formulating) masalah kehidupan nyata dalam istilah atau notasi matematis sehingga dapat diselesaikan (can be solved) sebagai masalah matematis dan solusi matematisnya dapat diterjemahkan (can be interpreted) untuk menjawab masalah nyata.

Proses pemodelan dilaksanakan secara utuh, bukan berupa proses parsial (Kaiser dan Sriraman, 2006: 32). Haines \& Crouch (Kaiser dan Sriraman, 2006: 32) menyatakan bahwa pemodelan dipahami sebagai aktivitas untuk menyelesaikan masalah autentik dan bukan sebagaimana pengembangan teori matematis.

Berkaitan dengan pemodelan matematika, Cai et al (2004: 6) menyatakan bahwa pemodelan matematis adalah seni atau proses membangun representasi matematis dari kenyataan yang menampilkan, menyimulasikan, atau 
merepresentasikan fitur terpilih atau perilaku dari aspek kenyataan yang dimodelkan. Hal ini menandakan bahwa pemodelan matematis berfokus pada representasi matematis.

Sebuah organisasi internasional bernama OECD (Organization for Economic Cooperation and Development), memberikan perhatian yang besar pada literasi matematika dan beberapa kecakapan abad 21 yang lain. OECD menyelenggarakan PISA (Programme for International Student Assessment) yaitu program penilaian terhadap kemampuan siswa di negaranegara peserta survey. Penilaian dilaksanakan setiap 3 tahun dengan penekanan berbeda di setiap periode penilaian. Penilaian terbaru yaitu pada tahun 2015 memprioritaskan sains (major), sedangkan membaca, matematika, penyelesaian masalah secara kolaboratif menjadi prioritas kedua (minor). Penilaian juga menjadikan finansial literacy sebagai focus penilaian pada Negara tertentu.

Berkaitan dengan literasi matematika, terdapat empat konten yang akan dinilai pada survey PISA 2018. Konten tersebut terdiri dari perubahan dan hubungan (change and relationships), ruang dan bentuk (space and shape), kuantitas dan ketidakpastian (quantity and uncertainty) (OECD, 2016: 84).

Berikut adalah perbandingan penilaian PISA pada dua periode terakhir.
Tabel 1. Jadwal Penilaian PISA pada Domain

\begin{tabular}{|c|c|c|c|}
\hline \multicolumn{5}{|c}{ Kognitif } \\
\hline PENILAIAN & 2012 & 2015 & 2018 \\
\hline Reading & minor & minor & major \\
\hline Mathematics & major & minor & minor \\
\hline Science & minor & major & minor \\
\hline Other & $\begin{array}{c}\text { problem } \\
\text { solving }\end{array}$ & $\begin{array}{c}\text { financial; } \\
\text { collaborat } \\
\text { ive } \\
\text { financial, } \\
\text { global } \\
\text { solving }\end{array}$ & $\begin{array}{c}\text { competen } \\
\text { ce }\end{array}$ \\
\hline
\end{tabular}

(Diadaptasi dari Stacey, 2010: 3)

Pada tahun 2018 akan dilaksanakan survey PISA yang ke delapan. Survey ini memiliki fokus yang berbeda dengan periode sebelumnya. Domain penilaian pada survey PISA 2018 meliputi literasi membaca, literasi matematika, literasi sains, literasi finansial, dan kompetensi global. Survey tersebut direncanakan paper-based dan computer-based.

Berikut adalah desain survey PISA 2018.

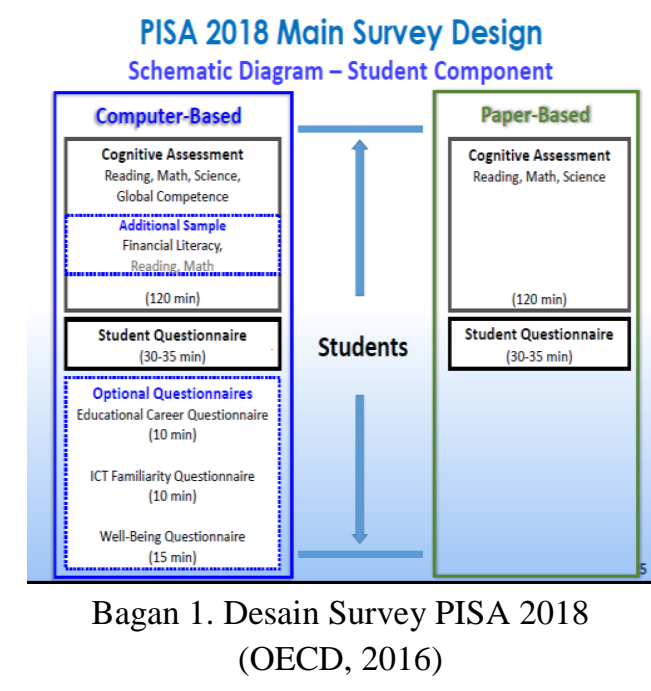

Literasi matematika pada survey PISA 2018 berkaitan dengan literasi finansial. Literasi finansial adalah pengetahuan dan pemahaman terhadap konsep finansial dan resiko, dan kemampuan terkait, motivasi dan kepercayaan diri untuk menerapkan pengetahuan dan pemahaman tersebut 
untuk membuat keputusan yang efektif lintas berbagai konteks keuangan, untuk meningkatkan kesejahteraan individu dan masyarakat, dan agar mampu berpartisipasi dalam kehidupan ekonomi (OECD, 2016: 58). OECD menegaskan bahwa yang dimaksud dengan "kemampuan terkait" adalah salah satunya berkaitan dengan literasi matematika. Kemampuan terkait meliputi kemampuan dasar dalam literasi matematika seperti kemampuan menghitung persentase, melakukan operasi matematika dasar atau mengkonversi dari satu mata uang ke yang lain, dan keterampilan bahasa seperti kapasitas untuk membaca dan menafsirkan iklan dan teks perjanjian kontrak (OECD, 2016: 59).

Dipandang dari aspek konten, terdapat irisan (intersects) antara literasi matematika dan literasi finansial. Irisan dalam hal ini yaitu penggunaan sejumlah soal aritmetika dasar yang mengharuskan siswa menerapkan pengetahuan dalam konteks finansial sehari-hari.

Capaian literasi matematika akan mempengaruhi capaian literasi finansial. OECD (2016: 86) menyatakan bahwa keterkaitan antara literasi finansial dan domain lain menunjukkan bahwa secara umum siswa yang lebih baik dalam literasi matematika dan/atau literasi membaca juga akan memiliki capaian yang lebih baik pada literasi finansial.

Rendahnya literasi matematika disebabkan oleh beberapa hal. Faktorfaktor yang memengaruhi prestasi siswa Indonesia pada studi PISA 2012 yaitu latar belakang peserta dari faktor internal yaitu jati diri siswa dan faktor eksternal yaitu kondisi keluarga, kepemilikan sarana belajar, dan kondisi sosial budaya di rumah dengan jati diri, kondisi sosial ekonomi dan budaya, kepemilikan komputer, dan buku-buku merupakan faktor utama yang memengaruhi capaian literasi matematika siswa Indonesia peserta PISA 2012 (Pakpahan, 2016: 331).

Kemampuan pengetahuan matematis yang rendah dipengaruhi beberapa faktor antara lain: 1) materi yang dipilih, 2) pembelajaran yang diberikan oleh guru, 3) lingkungan kelas, 4) dukungan lingkungan keluarga, 5) kesiapan dalam pelaksanaan tes dan 6) kemampuan yang dimiliki setiap siswa sendiri (Khoirudin, Setyawati, Nursyahida, 2017: 33). Selanjutnya Mahdiansyah dan Rahmawati (2014) menyatakan bahwa dari aspek konteks, scientific merupakan konteks yang paling rendah dicapai siswa; Adapun soal-soal tes yang mengukur kemampuan berpikir tingkat tinggi (higher orderthinking skills-HOTS) belum mampu dikuasai siswa dengan baik; Terdapat sejumlah faktor determinan dari capaian literasi matematika tersebut, yaitu faktor personal, faktor instruksional, dan faktor lingkungan; Kesimpulan studi adalah literasi matematika siswa jenjang pendidikan menengah masih rendah, meskipun desain tes internasional yang digunakan telah disesuaikan dengan konteks Indonesia. Tjalla (2010: 14) menyatakan bahwa skor rata-rata kemampuan matematika yang diperoleh siswa Indonesia masih di bawah ratarata negara OECD. Kemampuan matematika tersebut dipengaruhi oleh kemampuan yang masih rendah dalam hal: algoritma, menginterpretasi data, langkah-langkah dalam menyelesaikan 
problem, dan temuan dalam bidang matematika.

Berdasarkan hasil- hasil penelitian tersebut dapat disimpulkan bahwa faktor-faktor yang memengaruhi literasi matematika meliputi kondisi pembelajaran, dukungan orang tua, sarana dan prasarana pembelajaran, sumber belajar, kemampuan awal siswa berkaitan dengan penyelesaian masalah dan Higher Order Thinking Skill (HOTS).

Hal ini sejalan dengan model produktivitas pendidikan yang dikemukan oleh Walberg (Topcu, 2016: 1715) yang berguna sebagai framework untuk menguji prediktor prestasi matematika dan sains pada studi saat ini. Model tersebut meliputi: (a) variabel bakat siswa meliputi kemampuan/prestasi awal, motivasi/konsep diri dan usia/tingkat perkembangan; (b) variabel instruksional (pengajaran) meliputi kuantitas/waktu dan kualitas pengajaran, dan (c) variabel lingkungan meliputi rumah, ruang kelas, teman, paparan media massa.

Berdasarkan faktor-faktor yang telah dikemukakan dapat disusun beberapa upaya untuk meningkatkan literasi matematika. Berikut adalah upaya yang dikembangkan dari penelitian Topcu (2016: 1724-1727). Penelitian Topcu menggunakan konteks sains dan matematika yang dapat digunakan untuk menyusun rekomendasi dalam rangka mengembangkan literasi matematika.

\begin{tabular}{lrr}
\multicolumn{2}{c}{ Pertama, berdasarkan } & variabel \\
bakat & siswa & meliputi \\
kemampuan/prestasi & awal,
\end{tabular} motivasi/konsep diri dan usia/tingkat perkembangan. Kita harus menemukan metode strategi mengajar baru untuk mengurangi kecemasan terhadap matematika. Selanjutnya pada saat pembelajaran matematika, guru sebaiknya menunjukkan kegunaan matematika dengan membuat koneksi dalam kehidupan sehari-hari. Sekolah dapat mengenalkan pekerjaan berkaitan dengan matematika kepada siswa dan menekankan betapa belajar matematika dapat membuka banyak kesempatan kerja.

Berkaitan dengan sikap siswa, diperlukan tindakan pencegahan yang harus diambil oleh guru matematika dan orang tua siswa untuk meningkatkan sikap siswa terhadap matematika secara positif. Selanjutnya untuk meningkatkan sikap positif terhadap matematika, siswa harus terlibat secara aktif dalam tugas matematika yang bermanfaat yang didesain untuk membangkitkan rasa ingin tahu siswa dan untuk mendalami pemahaman konseptual.

Kedua, berkaitan dengan variabel lingkungan. Perlu dilakukan edukasi kepada orang tua untuk meningkatkan pengetahuan dan kesadaran terkait pendidikan. Hal ini penting dikarenakan tingkat pendidikan orang tua berkorelasi dengan prestasi siswa sebagaimana dinyatakan oleh Berberoğlu et al (Topcu, 2016: 1725). Selain itu, Willms (Topcu, 2016: 1725) menyarankan agar administrasi (pengelola) sekolah mendesain lingkungan sekolah dalam cara yang positif dan menarik untuk memotivasi siswa agar semakin bersemangat ke sekolah. Topcu juga mengemukakan isu bully dengan menyarankan kepada pengelola sekolah, guru, konselor, dan orang tua unuk 
proaktif dalam mencegah tindakan bully.

Berkaitan dengan variabel instruksional (pengajaran), efektivitas guru adalah sangat menentukan prestasi siswa. Hal ini berkaitan dengan kualitas pengajaran dan cara guru mengomunikasikan topik, tujuan pembelajaran, dan materi yang menarik dalam kelas matematika sebagaimana dirasakan oleh siswa. Secara spesifik berkaitan dengan literasi matematis yang akan dinilai pada survey PISA, guru perlu mengkondisikan siswa dengan pengalaman belajar yang berciri khas PISA. Ciri khas tersebut meliputi pendekatan pembelajaran, karakteristik masalah matematis, dan sikap sebagaimana dinyatakan dalam dokumen Kemdikbud (2007) di antaranya membiasakan siswa untuk menyelesaikan masalah matematis tipe PISA yang menekankan Higher Order Thinking Skill (HOTS). Selain itu, guru perlu membiasakan siswa untuk menyelesaikan masalah dengan konteks yang tidak familiar, meningkatkan keseriusan siswa dalam menyelesaikan masalah matematis.

\section{KESIMPULAN}

Literasi matematika adalah kemampuan individu untuk memformulasikan, menggunakan, dan menginterpretasikan matematika dalam berbagai konteks. Literasi mattematika merupakan salah satu kecakapan abad 21. Faktor-faktor yang mempengaruhi literasi matematika siswa meliputi (a) variabel bakat siswa meliputi kemampuan/prestasi awal, motivasi/konsep diri dan usia/tingkat perkembangan; $\quad$ (b) variabel instruksional (pengajaran) meliputi kuantitas/waktu dan kualitas pengajaran, dan (c) variabel lingkungan meliputi rumah, ruang kelas, teman, paparan media massa. Upaya yang dapat dilakukan dalam rangka pengembangan literasi matematika berkaitan dengan PISA 2018 adalah mengkondisikan siswa untuk terlibat dalam pengalaman belajar dengan pendekatan pembelajaran dan masalah matematis yang menekankan pada Higher Order Thinking Skill (HOTS) dan konteks yang tidak familiar serta mengembangkan sikap positif siswa.

\section{DAFTAR PUSTAKA}

Cai, et al. (2004). Mathematical Modeling in School Education: Mathematical, Cognitive, Curricular, Instructional, and Teacher Education Perspectives. [Online]. Tersedia: http://citeseerx.ist.psu.edu/viewdoc/ download;jsessionid=6D411BFCE7 92005F8757FC2352CDED26?doi= $\underline{10.1 .1 .689 .9756 \& r e p=r e p 1 \& \text { type }=p}$ df. [diakses 22 Mei 2018]

Kaiser, Gabriele dan Sriraman, Bharath. (2006). A Global Survey of International Perspectives on Modelling in Mathematics Education. ZDM. Vol. 38: 302-310.

Kementerian Pendidikan dan Kebudayaan. (2017). PISA Programme for International Student Assessment. [Online]. Tersedia: https://puspendik.kemdikbud.go.id/s eminar/index.php?folder=Sosialisasi \%20PISA\%202018. [diakses 22 Mei 2018]

Khoirudin, Setyawati, Nursyahida. (2017). Profil Kemampuan Literasi Matematika Siswa Berkemampuan Matematis Rendah dalam Menyelesaikan Soal Berbentuk PISA. Aksioma. Vol. 8: 33-42 
Mahdiansyah dan Rahmawati. (2014). Mathematical Literacy of Students at Secondary Education Level: An Analysis Using International Test Design with Indonesian Context. Jurnal Pendidikan dan Kebudayaan. Vol. 20: 452-469.

NEA. (2011). Preparing 21st Century Students for a Global Society: An Educator's Guide to the "Four $C s$ ". Washington: NEA

OECD. (2006). PISA 2012 Assessment and Analytical Framework: Mathematics, Reading, Science, and Problem Solving and Financial Literacy. Paris: OECD.

OECD. (2016). PISA 2018 Draft Analytical Framework May 2016. Paris: OECD.

OECD. (2016). PISA 2018 Integrated Design. Paris: OECD.

Ojose, Bobby. (2011). Mathematics Literacy: Are We Able To Put The Mathematics We Learn Into Everyday Use? Journal of
Mathematics Education. Vol. 4: 89-100.

Pakpahan. (2016). Factors Affecting Literacy Mathematics Achievement of Indonesian Student in PISA 2012. Jurnal Pendidikan dan Kebudayaan. Vol. 1: 331-348.

Stacey, Kaye. (2010). Mathematical and Scientific Literacy Around The World. Journal of Science and Mathematics Education in Southeast Asia. Vol. 33: 1-16.

Tjalla, Awaluddin. (2010). Potret Mutu Pendidikan Indonesia Ditinjau dari Hasil - hasil Studi Internasional. Psiko-Edukasi Jurnal Pendidikan, Psikologi, dan Konseling. Vol. 6: 100-120.

Topcu, Mustafa Sami. (2016). Factors Predicting Turkish and Korean Sttudents' Science and Mathematics Achievement in TIMSS 2011. Eurasia Journal of Mathematic, Science, and Technology Education. Vol. 12(7): 1711-1737. 